\title{
1 Seasonal development of iron limitation in the sub-Antarctic zone
}

2

3 Thomas J. Ryan-Keogh ${ }^{1,2}$, S. J. Thomalla ${ }^{1,2}$, T. N. Mtshali ${ }^{1}$, N. R. van Horsten ${ }^{1,3}$, H. Little ${ }^{2}$
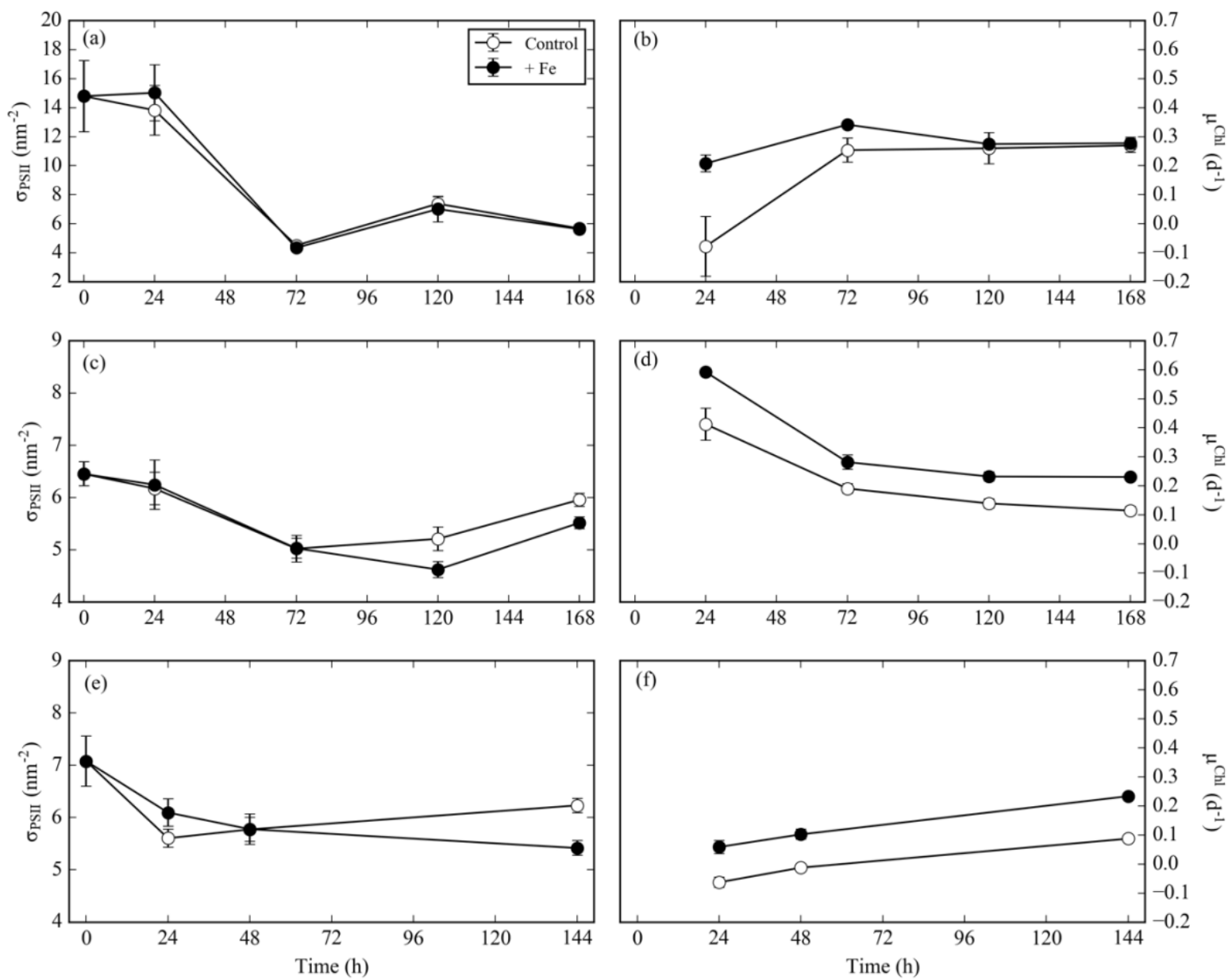

Figure S1: $\sigma_{P S I I}\left(\mathrm{~nm}^{-2}\right)(\mathrm{a}, \mathrm{c}, \mathrm{e})$ and chlorophyll-a specific growth rates $\left(\mathrm{d}^{-1}\right)(\mathrm{b}, \mathrm{d}, \mathrm{f})$, from

9 the control and Fe addition treatments of experiments initiated in the sub-Antarctic zone

10 over early summer $(a, b)$, mid-summer $(c, d)$, and late summer $(e, f)$. Displayed here are

11 averages with \pm standard deviations ( $n=3$ for all time points, except end time point where

$12 n=5)$. Please note the different scale in panel a, compared to $\mathrm{c}$ and $\mathrm{e}$. 

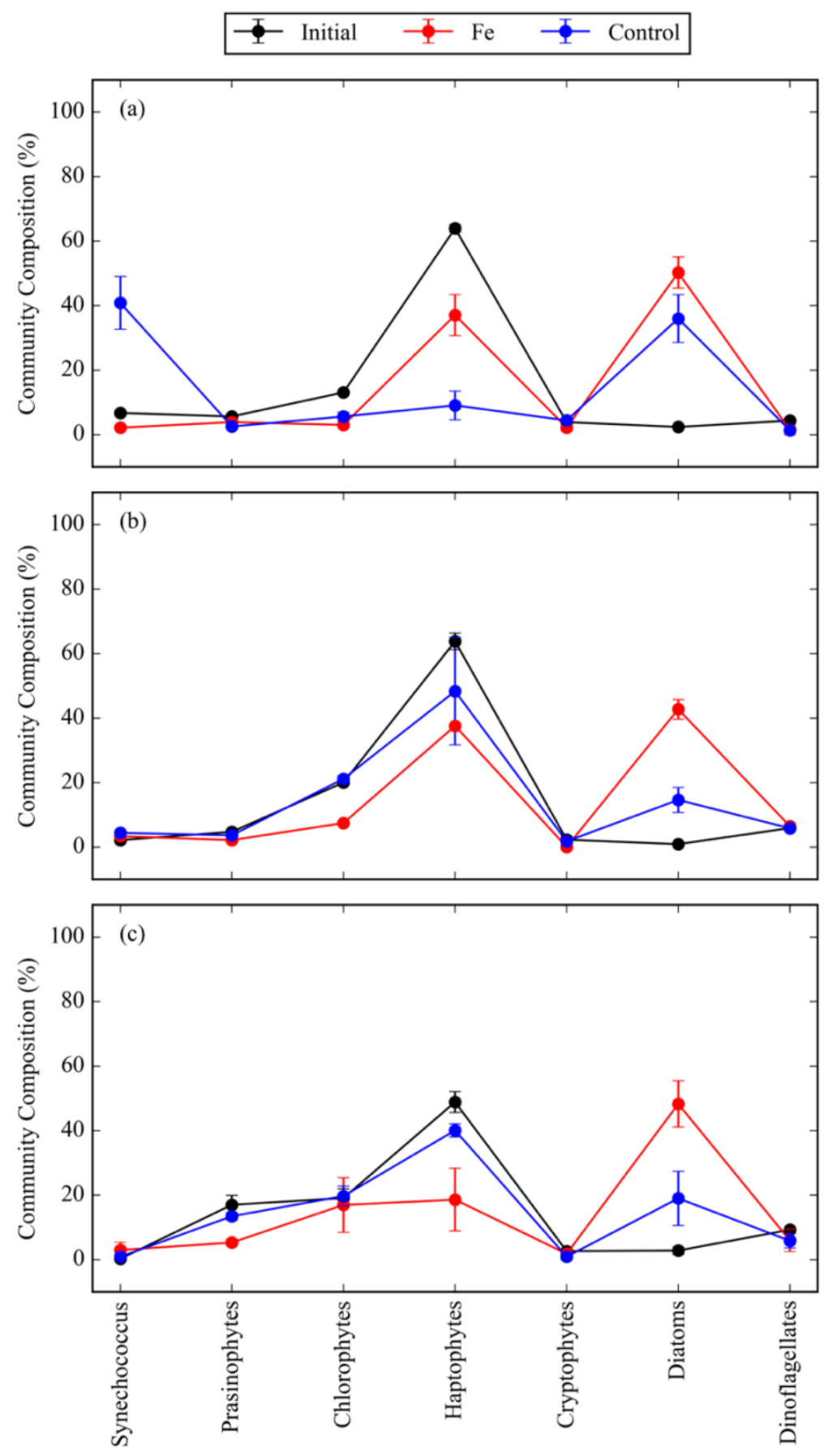

15 Figure S2: Community composition as a percentage of total chlorophyll a, determined by 16 HPLC (Ras et al., 2008) and CHEMTAX (Mackey et al., 1996), of experiments initiated

17 in early summer (a), mid-summer (b) and late summer (c). Initial community composition

18 in black $(t=0 \mathrm{~h})$, with end time point $(t=168,168$ and $144 \mathrm{~h}$ respectively) compositions

19 for the iron addition treatment in red, and the control treatment in blue. Displayed here

20 are averages with \pm standard deviations, where $n=3$. 